\title{
The Revealed Preference for Battery Electric Vehicle Range
}

\author{
Lasse Fridstrøm ${ }^{1}$ (D), Vegard $\varnothing$ stli $^{1}$ (D) \\ ${ }^{1}$ Institute of Transport Economics (TØI), Oslo \\ Keywords: battery electric cars, plug-in hybrids, range, non-linear utility, willingness-to-pay \\ https://doi.org/10.32866/001c.31635
}

Findings

Exploiting a disaggregate discrete choice model of automobile purchase, we reveal the willingness-to-pay for extended all-electric range in battery and plug-in hybrid electric cars in Norway. We find diminishing returns to range. By integration under the marginal willingness-to-pay curve, we calculate and plot the value of $100 \mathrm{~km}$ extended range. From an initial range of $150 \mathrm{~km}$, the revealed willingnessto-pay for $100 \mathrm{~km}$ longer range in a battery electric vehicle is around $€ 24000$.

When starting from an initial range of $500 \mathrm{~km}$, the value of another $100 \mathrm{~km}$ range drops to around $€ 5100$.

\section{Questions}

The primary drawback of battery electric vehicles (BEVs) as opposed to internal combustion engine (ICE) vehicles is their limited range. To enhance the competitiveness of BEVs, extended range might be useful. Exactly how do car buyers value battery electric range? How does the willingness-to-pay for extended range depend on the initial range?

\section{Methods}

The BIG-5.3 discrete choice model of automobile purchase is a disaggregate, generic nested logit model estimated on a data set including 2184804 individual new passenger car transactions between January 2003 and May 2019 in Norway. Without loss of information, we collapse the set of individual transactions into 40301 rows ('observations'), each describing a given model variant of which at least one specimen was sold in a given year. Weighting each observation by the number of identical model variants sold, we derive maximum likelihood estimates predicting the market share of each model variant in each year. For a more complete account of the model structure and estimation the reader is referred to Fridstrøm and Østli (2021a, 2021b).

In essence, the model distinguishes between five different energy technologies (market shares in 2020 in parentheses):

- Gasoline internal combustion engine (ICE) vehicles (6 percent)

- Diesel ICE vehicles (8 percent)

- Ordinary (non-plug-in) hybrid electric vehicles (HEVs) (11 percent)

- Plug-in hybrid electric vehicles (PHEVs) (20 percent)

- Battery electric vehicles (BEVs) (55 percent) 
Many vehicle demand models, including ours, treat the retail prices as exogenous. However, as pointed out in the seminal paper by Berry, Levinsohn, and Pakes (1995), automobile prices could be endogenous on account of unobserved product characteristics. This could bias our price coefficient towards zero.

We believe, however, to have reduced the scope for endogeneity bias by using the manufacturer's suggested retail prices, or 'list' prices, rather than the individual transaction prices negotiated between the individual customer and her car dealer, and by including a wide set of quality attributes among the explanatory factors, such as size, powertrain, ICE type approval fuel consumption and $\mathrm{CO}_{2}$ emissions per $\mathrm{km}, \mathrm{BEV}$ or PHEV electric range, traction (rear-, front- or 4-wheel), number of doors and seats, transmission, body style, and make (brand).

The upper nests of the model are defined as makes, while the lower level alternatives consist of the model variants offered within each make (Østli et al. 2017). Although the differences between certain car model variants are miniscule, they are all defined as separate units in the data set. There are 21 nests in the model, one for each of the 20 most common makes, plus a residual nest including 'all other makes'. In total, the model contains 84 parameters. All 21 scale parameters characterizing the lower nests come out larger than unity, as required for consistency with random utility maximization (Ben-Akiva and Lerman 1985).

The effect of electric range on utility cannot be assumed to be linear. To investigate this, the electric ranges of BEVs and PHEVs were specified, in our generic nested logit model, as flexible form Box-Cox functions (Box and Cox 1964; Gaudry and Wills 1978):

$$
x^{(\lambda)}= \begin{cases}\frac{x^{\lambda}-1}{\lambda} & \text { if } \lambda \neq 0(x>0) \\ \ln (x) & \text { if } \lambda=0(x>0)\end{cases}
$$

The Box-Cox parameter $\lambda$ determines the curvature of the relationship. $\lambda=2$ corresponds to a quadratic function, $\lambda=1$ to a linear one, $\lambda=0.5$ to a square root, $\lambda=0$ to a logarithmic function, and $\lambda=-1$ to a reciprocal one. The BoxCox function is continuous even for $\lambda=0$, since

$$
\lim _{\lambda \rightarrow 0}\left(\frac{x^{\lambda}-1}{\lambda}\right)=\ln (x) .
$$

Let $U_{i}$ denote the partial utility of all-electric range, let $p$ denote the vehicle's price, and let $r_{i}$ denote the all-electric range of cars with powertrain $i$. Then we can write 
Table 1. Disaggregate, generic nested logit model of automobile purchase. Selected coefficient estimates and standard errors.

\begin{tabular}{llll}
\hline Variable description & Variable name & Coefficient & Standard error \\
\hline Independent variables & & & \\
Log of size in square meters (length x width) & Size & 2.09 & 0.0123 \\
List price (100 kNOK 2019) & Price & -0.189 & 0.00107 \\
Net present value of energy outlay (100 kNOK 2019) & Energycost & -0.155 & 0.00211 \\
Non-tax share of list price & Resourcecostshare & 2.93 & 0.0167 \\
BEV electric range $(\mathrm{km})$, Box-Cox-transformed $\left(\lambda_{1}=-0.5\right)$ & BEVrange & 13.3 & 0.0890 \\
PHEV electric range $(\mathrm{km})$, Box-Cox-transformed $\left(\lambda_{2}=0.3\right)$ & PHEVrange & 0.0433 & 0.00201 \\
Diesel trend (log of years since 2001) & Dieseltrend & 0.257 & 0.00223 \\
General & & & \\
\# of parameters & & 84 & \\
\# of observation units & $\mathrm{k}$ & $\mathrm{n}$ & -16245144 \\
Initial log-likelihood & $\mathrm{n}$ & -14691044 \\
Final log-likelihood & $\mathrm{L}_{0}$ & 0.096 \\
Goodness-of-fit measure & $\mathrm{L}_{1}$ & $\rho^{2}$ & \\
\hline
\end{tabular}

Source: Fridstrøm and Østli (2021a).

$$
\begin{aligned}
U_{i} & =\alpha_{p} p+\alpha_{i} r_{i}^{\left(\lambda_{i}\right)}(i=1 \text { for } B E V s, 2 \text { for } P H E V s) \\
& =\left\{\begin{array}{cl}
\alpha_{p} p+\alpha_{i}\left(r_{i}^{\lambda_{i}}-1\right) / \lambda_{i} & \text { if } \lambda_{i} \neq 0 \\
\alpha_{p} p+\alpha_{i} \ln \left(r_{i}\right) & \text { if } \lambda_{i}=0
\end{array}\right.
\end{aligned}
$$

where $\alpha_{p}<0$ and $\alpha_{i}>0$ are slope coefficients, while $\lambda_{1}$ and $\lambda_{2}$ are Box-Cox (curvature) parameters.

The marginal willingness-to-pay for extended electric range can be computed as

$$
-\frac{\frac{\partial U_{i}}{\partial r_{i}}}{\frac{\partial U_{i}}{\partial p}}=-\frac{\alpha_{i}}{\alpha_{p}} r_{i}^{\lambda_{i}-1}
$$

The willingness-to-pay for larger improvements in range - from, say, $s_{0}$ to $s_{1}-$ can be computed as the integral under the curve (2):

$$
\begin{aligned}
W_{0}^{1} & =-\int_{s_{0}}^{s_{1}} \frac{\alpha_{i}}{\alpha_{p}} r_{i}^{\lambda_{i}-1} d r_{i} \\
& =-\frac{\alpha_{i}}{\lambda_{i} \alpha_{\mathrm{p}}}\left[s_{1}^{\lambda_{i}}-s_{0}^{\lambda_{i}}\right](i=B E V, P H E V)
\end{aligned}
$$

\section{Findings}

Selected results from the maximum likelihood estimation of our generic nested logit model are shown in Table 1.

To find the best-fit pair of Box-Cox parameters for BEVs and PHEVs, a grid search was performed, resulting in Box-Cox parameters of $\lambda_{1}=-0.5$ for BEVs and $\lambda_{2}=+0.3$ for PHEVs. 


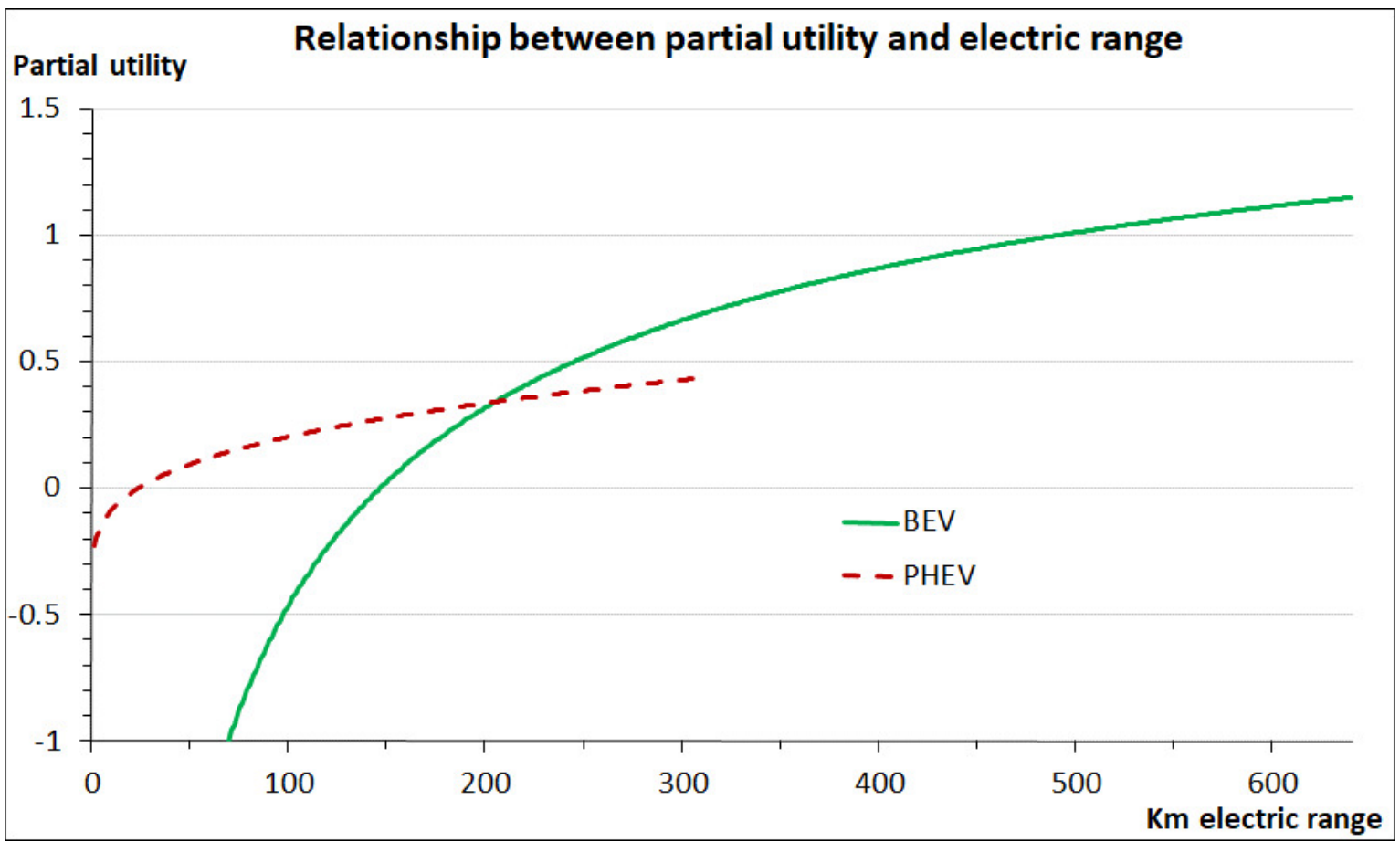

Figure 1. Estimated relationship between partial utility and all-electric range of BEVs or PHEVs.

With this specification, the price coefficient comes out at $\alpha_{p}=-0.189$ and the range coefficients at $\alpha_{1}=13.3$ and $\alpha_{2}=0.0433$ (Table 1 ).

The ensuing empirical Box-Cox partial utility functions (cf. equation 1) are depicted in Figure 1. The utility of a BEV or PHEV is a concave function of its (all-)electric range. Concavity is more pronounced for BEVs than for PHEVs.

The marginal willingness-to-pay for extended range (2) is plotted in Figure 2. At $150 \mathrm{~km}$ initial BEV range, the value of an extra kilometer BEV range comes out at NOK $3792=\mathrm{ca}$. $€ 354$ as converted at the July 1, 2020 exchange rate $(€$ $1=\mathrm{NOK} 10.70)$. At $500 \mathrm{~km}$ initial BEV range, the value drops to $\mathrm{NOK} 629=$ ca. $€ 59$ per $\mathrm{km}$.

For PHEVs, the marginal willingness-to-pay is much lower than for BEVs, coming out at NOK $1482=\mathrm{ca}$. $€ 139$ per $\mathrm{km}$ at $50 \mathrm{~km}$ initial all-electric range, and at NOK $912=\mathrm{ca}$. $€ 85$ at $100 \mathrm{~km}$ initial range.

In Figure 3, we exhibit the willingness-to-pay for $100 \mathrm{~km}$ extended range (3). At $150 \mathrm{~km}$ initial BEV range, the value is $\mathrm{NOK} 259000=\mathrm{ca}$. $€ 24200$. At 500 $\mathrm{km}$ initial BEV range, the value of a $100 \mathrm{~km}$ further extension has dropped to NOK $55000=$ ca. $€ 5140$.

Can these results be generalized to other countries or jurisdictions? We think yes, with some reservations.

Norway's record fast market uptake of battery and plug-in hybrid electric cars (75 percent in 2020) has given rise to an abundance of automobile transactions data fairly well balanced between the main five powertrain technologies. In our 


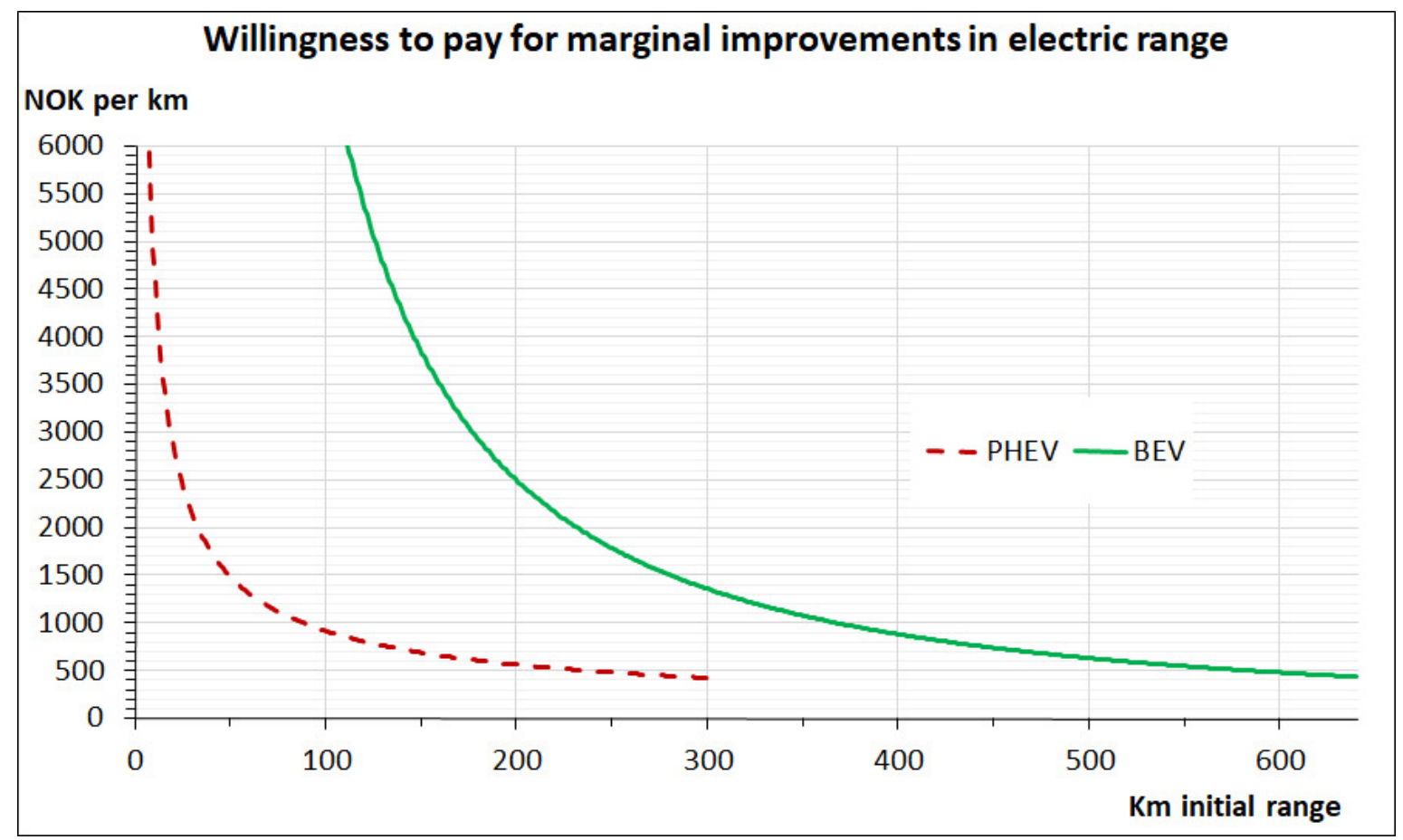

Figure 2. Estimated willingness-to-pay for marginal improvements in the all-electric range of BEVs or PHEVs.

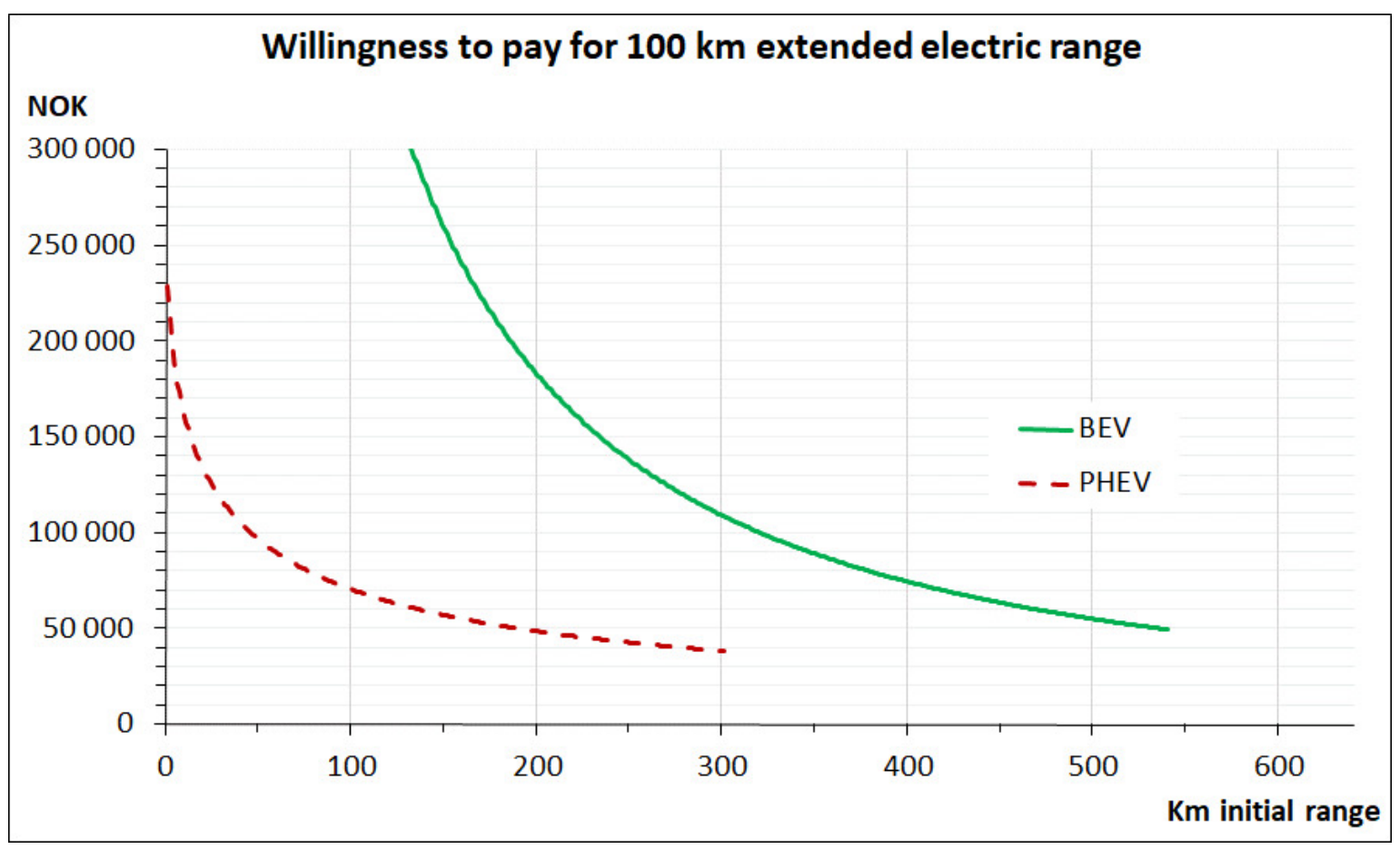

Figure 3. Estimated willingness-to-pay for $100 \mathrm{~km}$ extended all-electric range in BEVs or PHEVs.

empirical discrete choice model, we are able to control for a large number of vehicle attributes - including size, make, body style, list price, and energy costs - in order to distil the partial effect of electric range per se.

But we have not been able to take into account contextual factors that might be systematically different between Norway and other countries. Fridstrøm (2021) lists the following reasons why battery electric cars may be more 
competitive in Norway than elsewhere: cheap and abundant electricity, strong power grids, widespread (semi-)detached housing with garage or driveway, ample roadside space for fast charging facilities, slow roads, strong governance, high income, and pervasive tolling, from which zero emission vehicles might conceivably be exempted.

\section{Acknowledgements}

This research was funded by the Research Council of Norway (grant 280989 'Integrated Transport and Energy Modelling', grant 267942 'Driving Towards the Low-Emission Society', and grant 295789 'PLATON - a Platform for Open and Nationally Accessible Climate Policy').

Submitted: November 19, 2021 AEDT, Accepted: December 14, 2021 AEDT

This is an open-access article distributed under the terms of the Creative Commons Attribution 4.0 International License (CCBY-SA-4.0). View this license's legal deed at https://creativecommons.org/ licenses/by-sa/4.0 and legal code at https://creativecommons.org/licenses/by-sa/4.0/legalcode for more information. 


\section{REFERENCES}

Ben-Akiva, M., and S. R. Lerman . 1985. Discrete Choice Analysis: Theory and Application to Travel Demand. Cambridge, Mass: MIT Press.

Berry, S., J. Levinsohn, and A. Pakes. 1995. "Automobile Prices in Market Equilibrium.” Econometrica $63(4): 841-90$.

Box, G. E. P., and D. R. Cox. 1964. "An Analysis of Transformations.” Journal of the Royal Statistical Society B 26: 211-43.

Fridstrøm, Lasse. 2021. "The Norwegian Vehicle Electrification Policy and Its Implicit Price of Carbon.” Sustainability 13: 1346.

Fridstrøm, Lasse, and Vegard Østli. 2021a. “Bilavgiftenes Klimaeffekt.” TØI Report 1820. Oslo: Institute of Transport Economics.

- - - 2021b. "Direct and Cross Price Elasticities of Demand for Gasoline, Diesel, Hybrid and Battery Electric Cars: The Case of Norway.” European Transport Research Review 13 (January): 3. https://doi.org/10.1186/s12544-020-00454-2.

Gaudry, M., and M. I. Wills. 1978. "Estimating the Functional Form of Travel Demand Models.” Transportation Research 12: 257-89.

Østli, V., L. Fridstrøm, K. W. Johansen, and Y. Tseng. 2017. "A Generic Discrete Choice Model of Automobile Purchase.” European Transport Research Review 9: 16. 